\title{
REDUÇÃO DA EVAPORAÇÃO DE GOTICULAS CONTENDO HERBICIDA, COM EMPREGO DE OXIETILENO DOCOSANOL (')
}

\author{
HERMES GERALDO CORREA $\left({ }^{2}\right)$
}

\begin{abstract}
RESUMO
$O$ oxietileno docosanol (O.E.D) foi adicionado à calda de herbicida bentazone para conhecer o seu efeito no controle da evaporaçđo das gotículas pulverizadas. Sob condiçoes controladas de temperatura, umidade relativa e ausência de ventos, foram produzidas e utilizadas gotículas de determinados diâmetros para verificar a perda do volume através da redução do seu diâmetro em condiçoes estáticas e após a queda de $4,2 \mathrm{~m}$. Gotas de água mais herbicida, com diâmetro médio de 141 micros perderam $63 \%$ do seu volume e gotas de 216 micros perderam $30 \%$. Com a adiçøo de oxietileno docosanol a $0,5 \%$ em condiçđes idênticas, perdeu-se, com gotas de 134 micros, 15\% do volume e, com aquelas de 216 micros, apenas 9\%. Esses resultados concordam com aqueles obtidos com gotículas colhidas em fio de vidro, verificandose ao microscópio sua perda de volume através da redução do seu diâmetro.
\end{abstract}

Termos de indexação: evaporação de gotas; pulverização agrícola; oxietileno docosanol (O.E.D.)

\section{INTRODUÇĀO}

Atualmente a aplicação de defensivos na agricultura se faz utilizando a água como principal veículo de transporte, aderência e distribuição.

$\mathrm{Na}$ consecução desse objetivo, o líquido, ou melhor, a calda é fragmentada em gotículas com tamanho apropriado à circunstância em que o tra-

$\left(\begin{array}{l}1 \\ 2\end{array}\right)$ Recebido para publicação em 17 de janeiro de 1984.

( ${ }^{2}$ ) Seção de Máquinas de Implantação de Culturas e Aplicadoras de Defensivos, Instituto Agronômico (IAC), Caixa Postal 28, 13100 - Campinas (SP). 
tamento é realizado. Isso aumenta significativamente a superfície exposta do líquido, contribuindo para um elevado incremento de sua evaporação.

Ao evaporar, as gotículas perdem massa, tornando-se mais sujeitas ao arraste por correntes aéreas, disseminando-se no ecossistema, em áreas indesejáveis.

Dessa forma, o arraste ou deriva concorre para reduzir a deposição de princípio ativo na área tratada, com reflexos negativos para a cobertura foliar ou do solo, que se traduz no contato entre o princípio ativo e a superfície obje to do tratamento.

Na aplicação de herbicidas de contato, BUEHRING et alii (1973) apontaram a importância da cobertura proporcionada pelo maior volume da calda utilizado. Na aplicação aérea de herbicidas, porém, há uma séria restrição à utilização de alto volume, considerando as limitaçðes físicas impostas pela aparelhagem e também em vista ta economia da operação. De modo geral o volume dessas aplicaçбes não ultrapassa a faixa dos 40-50 litros por hectare.

Deve-se ainda considerar que nas aplicaçðes aéreas as gotículas são muito mais expostas à evaporação, pela turbulência gerada no ar com a passagem da aeronave e ao maior tempo despendido pela gotícula para atingir o alvo.

Existe na bibliografia ex tensa relação de pesquisa sobre a evaporação de pulverizaçסes (AKENSSON \& YATES, 1964; AMSDEN, 1962; BEHLEN, 1968; CUNNINGHAM et alii, 1962; GOERING et alii, 1972; MAKSYMIUK \& NEISESS, 1975), mas pouca investigação sobre o seu controle.

CORREA \& MAZIERO (1980) estudaram a evaporação de gotícula e seu controle empregando produtos antievaporantes. A maior parte dos produtos utilizados mostraram-se ineficientes para controle da evaporação, excetuando-se apenas o oxietileno docosanol.

No presente trabalho, procurou-se verificar o comportamento das gotas pulverizadas quando se adicionou o produto antievaporante à calda de defensivo, submetendo-as a uma queda no ar, em condiçoes controladas. Também foi verificado o comportamento das gotas em condiçóes estáticas. Este trabalho procura também contribuir para a geração de tecnologia básica de aplicação de defensivos.

\section{MATERIAL E MÉTODOS}

O número de gotas por centímetro quadrado dá origem à cobertura foliar que, principalmente para os herbicidas de contato, se relaciona 
diretamente com a eficiência do tratamento (DIDIO, 1977). A literatura mostra a necessidade mínima de 30 gotas com diâmetro de 200 a 1.000 micros/centímetro quadrado da superfície tratada, para que a aplicação aérea de herbicida seja eficiente (CORRECT. ., 1976). Para obter essa distribuição de gotas com o volume de 50 litros/hectare (baixo volume), há necessidade de se ter gotas com diâmetro médio aproximado de 317 micros. Todavia, esse cálculo não considerou as perdas na aplicação e a maior área da superfície foliar tratada em relação ao solo recoberto, fatores que reduzem o número de gotículas por unidade de superfície do alvo, e que devem ser considerados quando se trata de um herbicida de contato. Para compensar essa redução, escolheram-se gotículas menores do que aquelas calculadas, justificando assim o emprego de gotículas com diâmetro de $200 \mathrm{mi}-$ cros. $O$ ensaio foi complementado com gotículas de 100 micros, considerando que, na pulverização, obtém-se um espectro de gotas com vários diâmetros; daí, o interesse especial no comportamento das gotas pequenas, pelo perigo potencial de serem mais sujeitas à deriva.

$O$ estudo da evaporação da pulverização nas condiçðes de campo é muito difícil, uma vez que os fatores meteorológicos envolvidos (temperatura, umidade relativa, ventos) são muito variáveis. Por isso, realizou-se o ensaio II em recinto fechado, tendo em vista evitar interferência dos fatores mencionados.

Assim, foram conduzidos dois ensaios, sendo o primeiro para determinar a redução do diâmetro pela perda de volume das gotículas em condições estáticas e, o segundo, para verificar a redução do seu volume após queda.

\subsection{Ensaio I}

As gotículas foram produzidas por um pulverizador manual, marca Guarany, modelo Trombone, com deposito de 1 litro de capacidade, ao qual foi adaptado o bico cônico D 2-13 da Spraying Systems. Essas gotículas foram coletadas em fio de vidro segundo técnica desenvolvida por CORREA \& MAZIERO (1980), e imediatamente observadas em microscópio com retículo graduado e calibrado para selecionar as que apresentavam diâmetro adequado, anotando-se a intervalos regulares de tempo a redução de seu diâmetro (Figura 1). $\mathrm{O}$ microscópio estava equipado com lente ocular 10x e objetiva $20 x$.

Durante o ensaio, o recinto foi mantido à temperatura média de $22,5^{\circ} \mathrm{C}$ e à umidade relativa média de $67 \%$.

Duas classes de tamanho de gotas foram observadas: 100 e $200 \mathrm{mi}-$ 


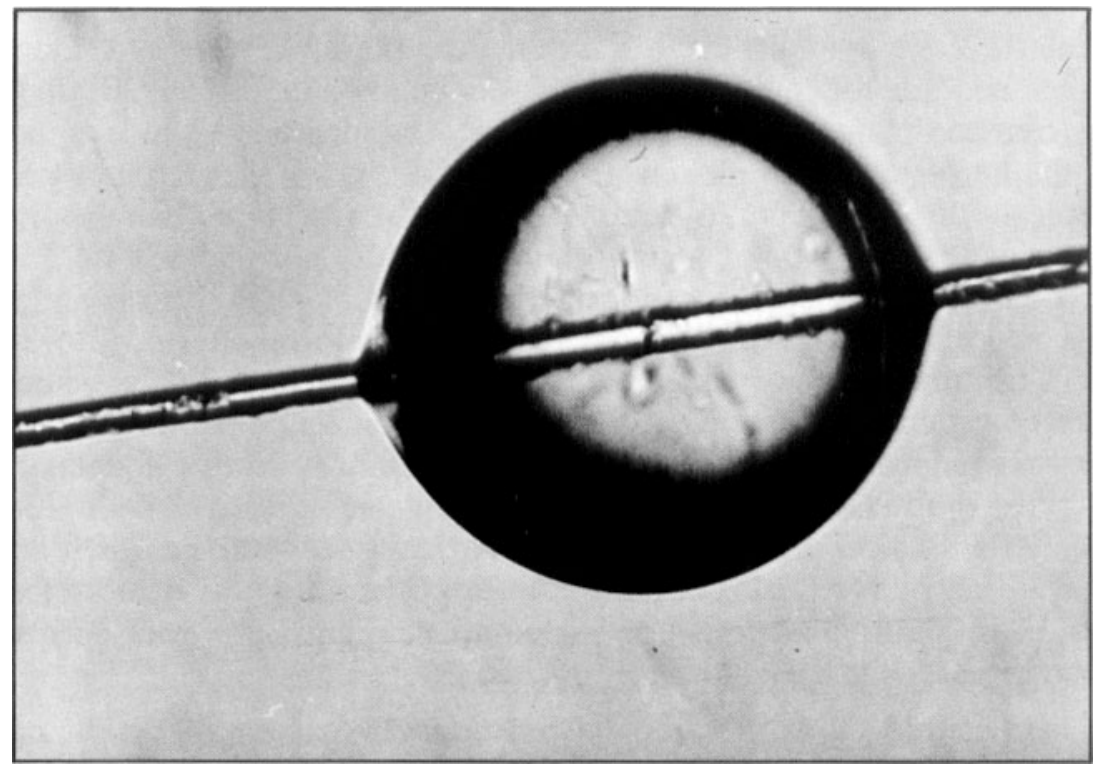

FIGURA 1 - Detalhe da técnica de amostragem de gotícula em fio de vidro

cros, sendo que em cada tamanho e tratamento as observaçoes foram repetidas quatro vezes. Os tratamentos foram os seguintes:
A - Água destilada + bentazone na concentração de $4,0 \%$ do pro- duto comercial;
B - Água destilada + antievaporante (O.E.D) a 0,5\% + bentazone a 4,0\% do produto comercial;
C - Agua destilada + antievaporante (O.E.D) a 1,0\%+ bentazone a $4,0 \%$ do produto comercial.

A marca registrada do herbicida utilizado foi o Basagran, que contém $480 \mathrm{~g}$ do sal sódico do bentazone por litro.

\subsection{Ensaio II}

Neste ensaio foi observada a redução do volume das gotículas quando cafram de $4,2 \mathrm{~m}$ no ar com temperatura média de $29^{\circ} \mathrm{C}$ e $47 \%$ de umidade relativa.

Com pulverizador centrifugo, gerador de gotas homogêneas, descrito por CORREA \& HELD (1982), selecionaram-se gotículas na faixa de 100 a 
200 micros $(118,134$ e 141) e na faixa acima de 200 micros (216 e 223). O pulverizador foi colocado em recinto fechado, à altura de $4,2 \mathrm{~m}$.

As gotículas foram lançadas bem próximo do ponto de encontro de duas paredes, tendo-se o cuidado de evitar corrente de ar que as desviasse da trajetória vertical.

Amostras das gotículas selecionadas foram coletadas simultaneamente em lâminas de papel kromekote de $7,5 \times 2,6 \mathrm{~cm}$, logo depois de terem sido lançadas pelo aparelho e ao nível do solo. Para possibilitar a visualização das got ículas no papel, foi adicionada nigrosina a $0,4 \%$ no líquido a ser pulverizado. $O$ fator de espalhamento foi determinado segundo técnica já descrita (CORREA \& HELD, 1982). A diferença de volumes entre os dois pontos de amostragem foi calculada pela redução do diâmetro das gotas e expressa em porcentagem do volume inicial: essa porcentagem representa a redução do volume devida à evaporação.

Foram realizadas quatro amostragens de cada tratamento, sendo computadas 50 gotas de cada amostragem. Os tratamentos deste ensaio foram os seguintes:

A: Água destilada + nigrosina a 0,4\%;

B: Água destilada + nigrosina a $0,4 \%$ + bentazone a $4,0 \%$ do produ to comercial;

C: Agua destilada + nigrosina a $0,4 \%+$ bentazone a $4,0 \%$ do produto comercial + oxietileno docosanol a $0,5 \%$.

A concentração de $4,0 \%$ do herbicida foi escolhida com base na recomendação do fabricante para aplicar 2 litros do produto comercial por hectare. Utilizando 50 litros de água por hectare, ter-se-á o produto na concentração usada neste ensaio.

\section{RESULTADOS E DISCUSSAXO}

As perdas percentuais de volume das gotículas do ensaio I são apresentadas nos quadros 1 e 2 . As figuras $2{ }^{\circ} 3$ apresentam as perdas de volume das gotículas de 100 e 200 micros de diâmetro, colhidas em fio de vidro.

Verifica-se nesses quadros que gotículas de água e bentazone com 200 micros perderam por evaporação $95 \%$ do seu volume no final de $120 \mathrm{~s}$ com gotículas de 100micros; o mesmo sucedeu em 40s.

A adição do antievaporante, oxietileno docosanol (O.E.D.) à calda contendo defensivo mostrou-se eficiente para reduzir a evaporação das gotas, no primeiro ensaio. Entretanto, a utilização do O.E.D. a 1,0\% induziu 
diferença muito pequena na taxa de evaporação dos dois tamanhos de gotículas experimentados, em relação àquela obtida com $0,5 \%$ do produto.

QUADRO 1 - Ensaio I - Perda percentual do volume das gotículas de 100 micros, suspensas em fio de vidro, em função do tempo

\begin{tabular}{|c|c|c|c|c|c|c|}
\hline \multirow{2}{*}{$\begin{array}{c}\text { Tempo } \\
\text { de } \\
\text { observação } \\
\text { (segundo) }\end{array}$} & \multicolumn{6}{|c|}{ Porcentagem de redução do volume } \\
\hline & $\begin{array}{c}\text { Ägua } \\
+ \\
\text { bentazone }\end{array}$ & $\mathrm{CV}$ & $\begin{array}{c}\text { Ảgua }+ \\
\text { bentazone } \\
+0,5 \% \text { de O.E.D.* }\end{array}$ & $\mathrm{CV}$ & $\begin{array}{c}\text { Ȧgua }+ \\
\text { bentazone } \\
+1,0 \% \text { de O.E.D. }\end{array}$ & $\mathrm{CV}$ \\
\hline & & $\%$ & & $\%$ & & $\%$ \\
\hline 10 & 27 & 0 & 0 & - & 0 & - \\
\hline 20 & 53 & 4 & 0 & - & 0 & - \\
\hline 30 & 81 & 9 & 0 & - & 0 & - \\
\hline 40 & 95 & 17 & 0 & - & 0 & - \\
\hline 50 & 97 & 15 & 0 & - & 0 & - \\
\hline $60(1 \mathrm{~min})$ & 97 & 8 & 0 & - & 0 & - \\
\hline 90 & 97 & 8 & 0 & - & 0 & - \\
\hline $120(2 \mathrm{~min})$ & 97 & 8 & 0 & - & 2 & 1 \\
\hline 150 & ... & $\ldots$ & 2 & 1 & 7 & 2 \\
\hline $180(3 \mathrm{~min})$ & $\ldots$ & $\ldots$ & 6 & 2 & 13 & 1 \\
\hline $240(4 \mathrm{~min})$ & .. & $\ldots$ & 16 & 1 & 18 & 2 \\
\hline $300(5 \mathrm{~min})$ & $\ldots$ & $\ldots$ & 21 & 2 & 24 & 2 \\
\hline $600(10 \mathrm{~min})$ & $\ldots$ & $\ldots$ & 40 & 4 & 40 & 4 \\
\hline $900(15 \mathrm{~min})$ & $\ldots$ & $\ldots$ & 58 & 5 & 56 & 4 \\
\hline $1800(30 \mathrm{~min})$ & $\ldots$ & $\ldots$ & 90 & 5 & 87 & 9 \\
\hline
\end{tabular}

$\left({ }^{*}\right)$ Oxietileno docosanol.

Admitindo uma taxa de evaporação constante nos intervalos de tempo considerados, com 22s, as gotículas de água + bentazone com 100 micros, perderam $58 \%$ do seu volume, e quando se adicionou docosanol, igual volume foi perdido em $15 \mathrm{~min}$, portanto com O.E.D. a evaporação é 41 vezes mais lenta. Esse resultado se aproxima daquele obtido em ensaios anteriores (CORREA \& MAZIERO, 1980), quando se empregaram gotículas de água pura com 145 micros, as quais perderam $58 \%$ do seu volume em $43 \mathrm{~s}$, e quando se adicionou o oxietileno docosanol a $0,5 \%$, igual volume da gotícula se evaporou em $30 \mathrm{~min}$, sendo neste caso a evaporação 42 vezes mais lenta. 
QUADRO 2 - Ensaio I - Perda percentual do volume das gotículas de 200 micros, suspensas em fio de vidro, em função do tempo

\begin{tabular}{|c|c|c|c|c|c|c|}
\hline \multirow{2}{*}{$\begin{array}{c}\text { Tempo } \\
\text { de } \\
\text { observação } \\
\text { (segundo) }\end{array}$} & \multicolumn{6}{|c|}{ Porcentagem de redução do volume } \\
\hline & $\begin{array}{c}\text { Água } \\
+ \\
\text { bentazone }\end{array}$ & $\mathrm{CV}$ & $\begin{array}{c}\text { Água }+ \\
\text { bentazone } \\
+0,5 \% \text { de O.E.D.* }\end{array}$ & $\mathrm{CV}$ & $\begin{array}{c}\text { Água }+ \\
\text { bentazone } \\
+1,0 \% \text { de O.E.D. }\end{array}$ & ${ }_{*}^{\mathrm{CV}}$ \\
\hline & & $\%$ & & $\%$ & & $\%$ \\
\hline 10 & 8 & 0 & 0 & - & 0 & - \\
\hline 20 & 16 & 2 & 0 & - & 0 & - \\
\hline 30 & 29 & 4 & 0 & - & 0 & - \\
\hline 40 & 37 & 4 & 0 & - & 0 & - \\
\hline 50 & 55 & 10 & 0 & - & 0 & - \\
\hline $60(1 \mathrm{~min})$ & 67 & 10 & 0 & - & 0 & - \\
\hline 90 & 88 & 20 & 1 & 1 & 0 & - \\
\hline $120(2 \mathrm{~min})$ & 95 & 6 & 1 & 1 & 0 & - \\
\hline 150 & 96 & 6 & 6 & 1 & 3 & 1 \\
\hline $180(3 \mathrm{~min})$ & 96 & 6 & 6 & 1 & 3 & 1 \\
\hline $240(4 \mathrm{~min})$ & 96 & 6 & 12 & 1 & 7 & 2 \\
\hline $300(5 \mathrm{~min})$ & ... & $\ldots$ & 15 & 2 & 10 & 2 \\
\hline $600(10 \mathrm{~min})$ & $\ldots$ & $\ldots$ & 28 & 2 & 23 & 2 \\
\hline $900(15 \mathrm{~min})$ & $\ldots$ & $\ldots$ & 37 & 1 & 32 & 3 \\
\hline $1800(30 \mathrm{~min})$ & $\ldots$ & $\ldots$ & 61 & 2 & 59 & 3 \\
\hline
\end{tabular}

(*) Oxietileno docosanol.

No presente ensaio, a mesma investigação foi realizada com gotículas de 200 micros, verificando que elas perderam em $52 \mathrm{~s}$ igual volume que aquelas que continham o oxietileno docosanol perderam em $28 \mathrm{~min}$, ou seja, $58 \%$ do volume inicial, obtendo-se, portanto, uma evaporação 32 vezes mais lenta com o antievaporante. Isso revela uma tendência de maior ação do oxietileno docosanol nas gotas menores.

Por ser o volume uma função cúbica do diâmetro, compreende-se que, quando reduzem o diâmetro original à metade, as gotículas apresentam um volume remanescente de apenas $12,5 \%$. A análise da perda de volume por unidade de tempo indica que as gotículas menores apresentam taxa de evaporação maior, de modo que a evaporação da água nas gotas está condicionada ao tamanho delas (CUNNINGHAM et alii, 1962; MAAS, 1971). 


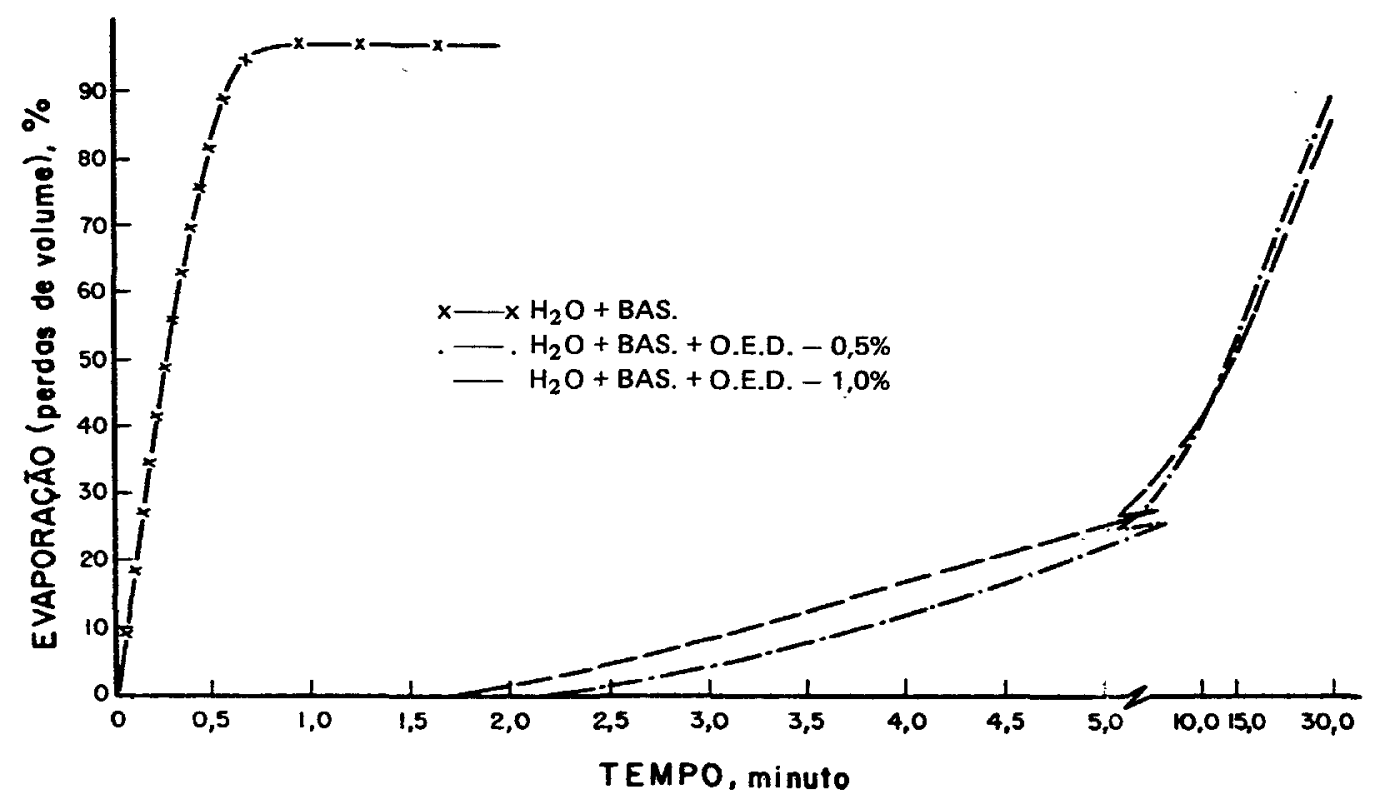

FIGURA 2 - Evaporação de gotas de 100 micros de diâmetro colhidas em fio de vidro e em ambiente com $67 \%$ de umidade e $22,5^{\circ} \mathrm{C}$.

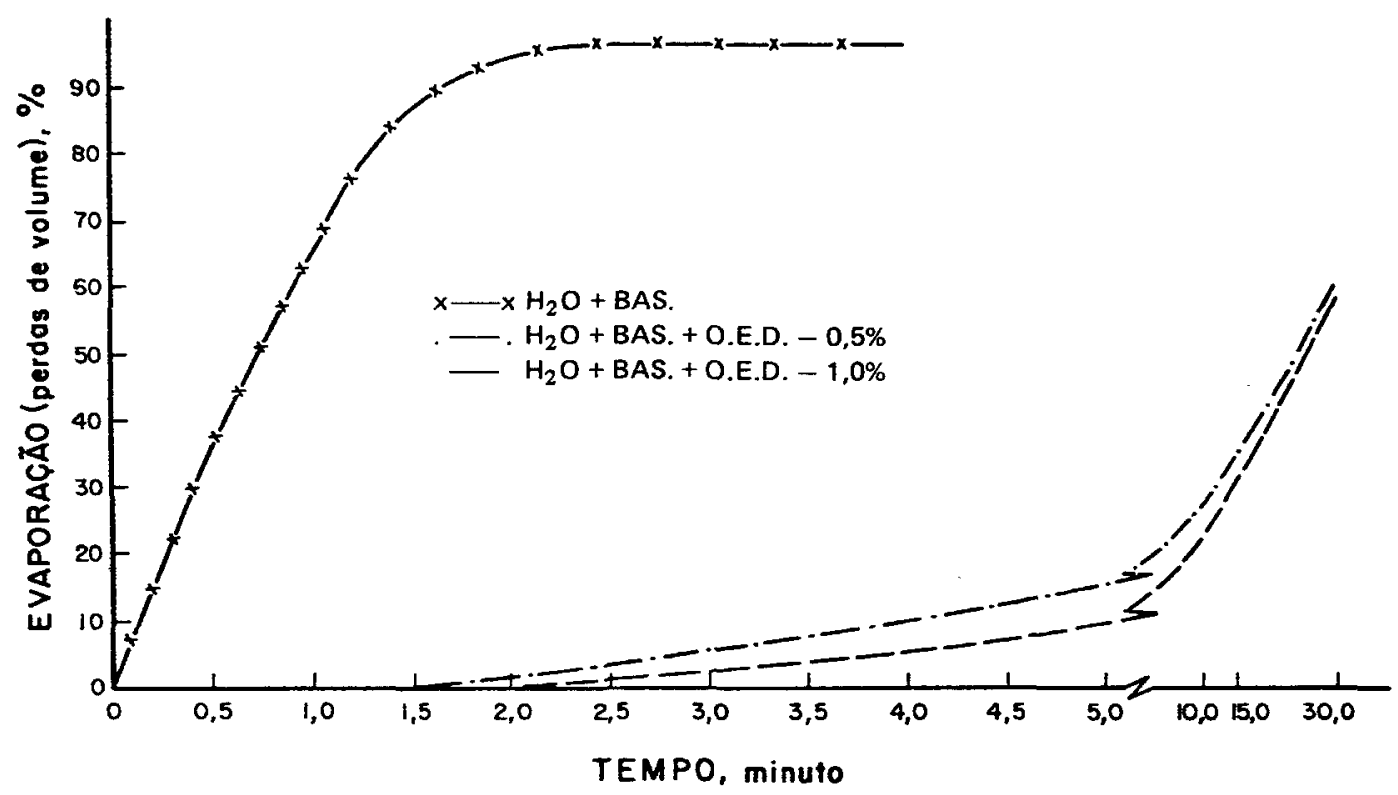

FIGURA 3 - Evaporação de gotas de 200 micros de diâmetro colhidas em fio de vidro e em ambiente com $67 \%$ de umidade e $22,5^{\circ} \mathrm{C}$. 
Quando se divide um volume líquido em goticulas, há um aumento da sua superfície à medida que o tamanho das gotículas diminui.

Os resultados obtidos no ensaio de evaporação de gotas confirmam esta análise, visto que a maior área exposta em relação ao volume fez com que as gotículas de 100 micros reduzissem seu volume mais rapidamente do que aquelas de 200 micros.

A relação $\mathrm{S} / \mathrm{V}$ (superfície/volume) para gotas de 100 micros é 0,06 (tomando o micro por unidade), enquanto para as de 200 micros é 0,03 .

A adição do produto antievaporante ao líquido que será pulverizado tem a finalidade de formar uma película envolvente na gotícula, modificando assim o processo de sua evaporação.

CORREA \& MAZIERO (1980) mostram que na concentração de $0,5 \%$, o álcool foi eficiente para reduzir a evaporação de gotículas de 145 micros. Segundo o produtor do álcool, uma película monomolecular do mesmo com espessura de $1 / 300.000 \mathrm{~mm}$, que corresponde ao tamanho da molécula de O.E.D., já é eficaz.

Pode-se calcular o diâmetro no qual a concentração do álcool ainda é suficiente para proporcionar uma película envolvente monomolecular com a espessura citada, ou seja,

$$
E=r-r^{3}\left(1-C \cdot 10^{-2}\right)^{1 / 3}
$$

onde: E é a espessura, em micro, da película envoltória; r, o raio, em micro, da gotícula utilizada; $C$, a concentração percentual do O.E.D.

Essa formula evidencia que, reduzindo o tamanho das gotículas, há necessidade de aumentar a concentração do O.E.D. na calda para manter a mesma espessura da película envolvente.

Os dados apresentados no quadro 3 assemelham-se aos obtidos na evaporação de gotículas coletadas em fio de vidro apresentados nos quadros $1 \mathrm{e} 2$. Em todos os tratamentos, as gotas menores perderam maior porcentagem de volume. Todavia, deve-se considerar neste ensaio a diferente velocidade de queda das gotas. Como essa velocidade é uma função do diâmetro, as gotas menores, com menor velocidade, permaneceram mais tempo no ar expostas à evaporação, o que evidentemente agravou a perda de seu volume.

A velocidade terminal, ou seja, a velocidade atingida pela gota em queda no ar, é regida pela lei de Stokes, com interaçạo da turbulência gerada, em se tratando de gotas com diâmetro superior a 100 micros (BROOKS, 1947). Como no percurso a gotícula passou por uma gradual redução do diâmetro, entende-se que sua velocidade variou continuamente durante o trajeto. 
QUADRO 3 - Redução do diâmetro das gotículas e porcentagem de evaporação (altura de lançamento: $4,2 \mathrm{~m}$ )

\begin{tabular}{lccccc}
\hline Tratamentos & $\begin{array}{c}\text { Diâmetro } \\
\text { inicial }\end{array}$ & CV & $\begin{array}{c}\text { Diâmetro } \\
\text { final }\end{array}$ & CV & Evaporação \\
\hline & micro & $\%$ & micro & $\%$ & $\%$ \\
Āgua + nigrosina & 118 & 5 & 82 & 12 & 66 \\
& 223 & 2 & 187 & 4 & 41 \\
$\begin{array}{l}\text { Água + nigrosina } \\
+ \text { bentazone }\end{array}$ & 141 & 7 & 101 & 12 & 63 \\
$\begin{array}{l}\text { Água + nigrosina } \\
+ \text { bentazone + O.E.D.* }\end{array}$ & 216 & 6 & 192 & 6 & 30 \\
\hline
\end{tabular}

(*) Oxietileno docosanol.

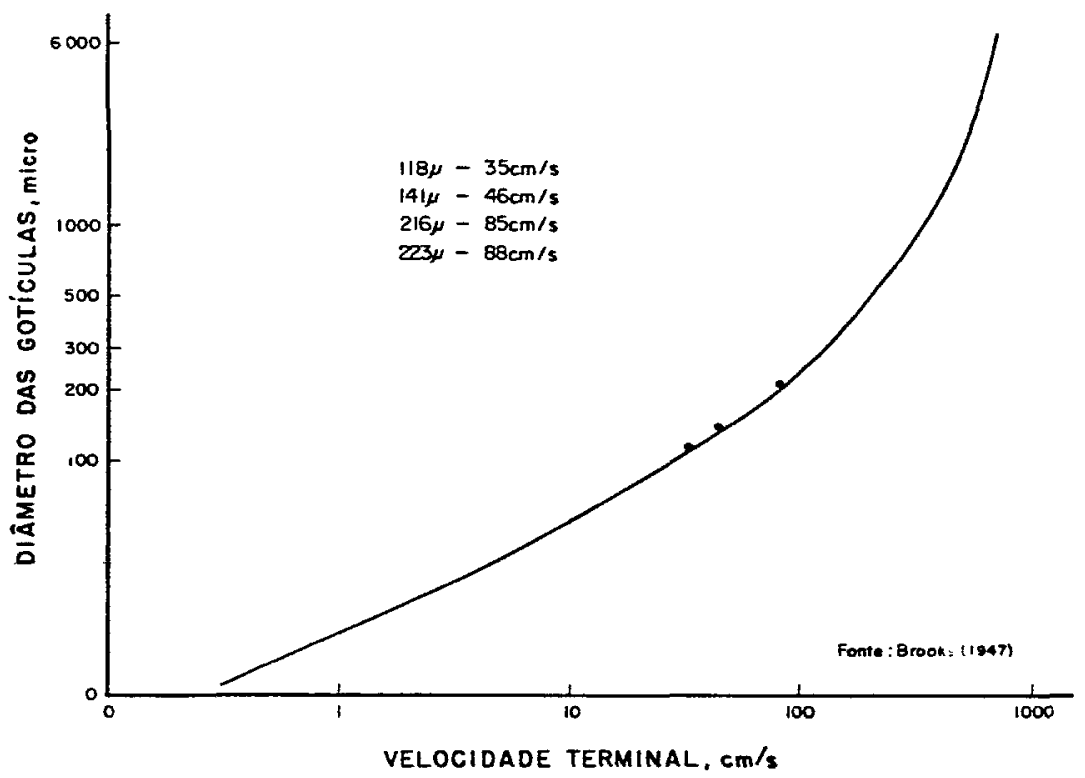

FIGURA 4 - Velocidade terminal (cm/s) em função do diâmetro das gotículas d'água 
Se não houvesse gradativa evaporação e a velocidade terminal se mantivesse constante, de acordo com a figura 4, as gotas de 216-223 micros apresentariam a velocidade terminal média de $86 \mathrm{~cm} / \mathrm{s}$, requerendo aproximadamente $5 \mathrm{~s}$ para percorrer a distância de $4,2 \mathrm{~m}$ utilizada. As gotas menores (134 a 141 micros) requereriam cerca de $9,3 \mathrm{~s}$, com uma velocidade terminal média de $45 \mathrm{~cm} / \mathrm{s}$.

Depreende-se disso que dois fatores se adicionaram para que as gotas pequenas apresentassem maior perda por evaporação: a maior superfície exposta do líquido e o maior tempo despendido no percurso até o solo.

Em situaçбes análogas, deve-se considerar o aumento da concentração do defensivo quando a gotícula perde água por evaporação, admitindo que a evaporação do defensivo seja insignificante. No experimento em pauta, nas gotas de 141 micros do tratamento $B$, a concentração do herbicida aumentou consideravelmente de 4 para $11 \%$. Tratando-se de herbicida seletivo, faz-se necessário verificar a possível fitotoxicidade à cultura, considerando que pode ocorrer a evaporação total da água, a ponto de o defensivo depositar-se à concentração máxima, ou seja, sem diluição, sobre a vegetação (culturas e ervas a serem controladas).

\section{CONCLUSOES}

A aplicação de herbicida bentazone quando se utilizou apenas água para a elaboração da calda, apresentou acentuada redução do tamanho das gotículas pela evaporação. Em ensaio estático utilizando gotículas de $100 \mathrm{mi}-$ cros captadas em fio de vidro, sua evaporação total se deu em $2 \mathrm{~min}$, e aquelas de 200 micros em $3 \mathrm{~min}$.

A utilização de oxietileno docosanol a $0,5 \%$ retardou a evaporação, de modo que as gotículas de 100 micros perderam, em média, $90 \%$ do volume em $30 \mathrm{~min}$, enquanto aquelas com diâmetro de 200 micros perderam $61 \%$ do volume no mesmo tempo. Aumentando a. concentração do antievaporante para $1 \%$, as gotas de 100 e 200 micros perderam, respectivamente, 87 e $59 \%$ do seu volume em $30 \mathrm{~min}$, mostrando que, dobrando a concentração do antievaporante, a redução da evaporação não apresentou a mesma proporção.

Quando as gotas foram aplicadas em condições que simulam aquelas da aplicação aérea pela queda no ar, gotas de 141 micros de diâmetro inicial perderam $63 \%$ do volume original até caírem ao solo, enquanto gotas com 216 micros perderam $30 \%$ do seu volume, uma perda ainda considerada alta.

Quando se adicionou antievaporante à calda contendo o herbicida, 
gotas menores (134 micros) apresentaram perda de apenas $15 \%$, enquanto nas maiores ( 216 micros), a reduçáo do volume caiu a $9 \%$.

Em situaçסes semelhantes àquelas do ensaio, quando não se emprega antievaporante, utilizando gotas maiores ( 220 micros), é necessário um volume adicional para proporcionar os mesmos resultados na cobertura do alvo.

Este acréscimo de volume será um pouco inferior a $21 \%$, conforme foi calculado pela diferença entre a perda do volume da gotícula sem o antievaporante $(30 \%)$ e aquela obtida com a adição do antievaporante $(9 \%)$, considerando que, nesta situação, a razão de evaporação das gotas sofre alteraçōes de acordo com o seu diâmetro. A mesma observação é válida para compensar a evaporação da calda aquosa das gotas menores (134 a $141 \mathrm{mi}-$ cros), quando é requerido um volume inferior a $48 \%$ (63\% menos $15 \%$ ).

Esses resultados revelam que a utilização do antievaporante se apresenta promissora para aplicação aérea do defensivo empregado.

\title{
SUMMARY \\ REDUCTION OF DROPLET HERBICIDE EVAPORATION USING OXIETHYLENE DOCOSANOL
}

\begin{abstract}
This experiment was conducted to test the use of oxiethylene docosanol (O.E.D.) to reduce the loss of water during the spray of contact herbicide (bentazone). The droplets were produced under controlled conditions of temperature, relative humidity and absence of wind. The loss of volume was calculated by measuring the reduction of droplet diameter after a fall of $4.2 \mathrm{~m}$. When the herbicide solution without O.E.D. was sprayed there was a loss of $63 \%$ of the initial volume for the small droplets (141 micra) and $30 \%$ for the large droplets ( $216 \mathrm{mjcra}$ ). When O.E.D. was added to the herbicide the volume loss was reduced to $15 \%$ and $9 \%$, respective$\mathrm{ly}$, for the smaller (134 micra) and larger droplets (216 micra).
\end{abstract}

Index terms: droplet evaporation; spraying; pest control; oxiethylene docosanol.

\section{AGRADECIMENTOS}

Apresentamos ao Dr. Nelson Paulieri Sabino, chefe da Seção de Tecnologia de Fibras, na ocasião em que este trabalho foi realizado, sinceros agradecimentos pela disposição colaboradora ao permitir que utilizássemos as instalaçסes, com umidade e temperatura do ar controladas para realização desta experimentação.

Ao Dr. Tomomassa Matuo, professor do Departamento de Tratamento Fitossanitário da Faculdade de Ciências Agrárias e Veterinárias de Jaboticabal, agradecemos a revisão e sugestðes apresentadas na redação do trabalho. 


\section{REFERÊNCIAS BIBLIOGRÁFICAS}

AKENSSON, N.B. \& YATES, W.E. Problems relating to application of agricultural chemicals and resulting drift residues. Annual Review of Entomology, 9:285-318, 1964.

AMSDEN, R.C. Reducing the evaporation of sprays. Agricultural Aviation, 4:88-93, 1962.

BEHLEN, W. "Synergid 3" an invention of particular value to agricultural aviation. Agricultural Aviation, 10(3):8486, 1968.

BROOKS, F.A. The drifting of poisonous dusts applied by airplanes and land rigs. Agricultural Engineering, 28(6):233-239, 244, 1947.

BUEHRING, N.W.; ROTH, L.D. \& SANTELMANN, P.W. Plant response to herbicide spray drop size and carrier volume. Transactions of the ASAE, 16(4): 636-638, 1973.

CORREA, H.G. \& HELD, J. de. Produção e utilização de gotas com diâmetro uniforme. Bragantia, Campinas, 41(1): 1-9, 1982.

\& MAZIERO, J.V.G. Análise em laboratório da redução da evaporação de gotículas para pulverizaçסes agrícolas, Bragantia, Campinas, 39(10): 79-87, 1980.

CORRECT aerial application of pesticides. Basle, Switzerland, Ciba-Geigy Ltd., 1976, 30p. (Boletim Técnico)

CUNNINGHAM, R.T., BRANN JR., J.L. \& FLEMING, G.A. Factors affecting the evaporation of water from droplets in airblast spraying. Journal of Economic Entomology, 55(2): 192-198, 1962.

DIDIO, J.R. Técnica de aplication Y biologia. Curso de instrucción - Técnicas de Aplicación AC6.21. Basle, Switzerland, Ciba-Geigy, 1977. 12p.

GOERING, C.E.; BODE, L.E. \& GEBHARDT, M.R. Mathematical modeling of spray droplet deceleration and evaporation. Transactions of the ASAE, 15(2): 220-225, 1972.

MAAS, W. ULV application and formulation techniques. Amsterdam, N.V. Philips-Duphar-Crop protection Division, 1971. 165p.

MAKSYMIUK; B., \& NEISESS, J. Physical properties of Bacillus thuringiensis spray formulations. Journal of Economic Entomology, 68(3): 407$410,1975$. 